\title{
On Cultivating Traditional Cultural Quality in English Majors in China
}

\author{
YANG Yi, WANG Bing, YANG Yuan \\ Leshan Normal University, Leshan, China
}

\begin{abstract}
In the age of economic globalization, China has accelerated internationalization process in domestic economy and culture, which brings both challenges and opportunities to English majors — for one thing, good foreign language skill is required and for another thing, good knowledge of traditional culture is also needed. Because of the excellent college education, many English majors have mastered a foreign language to some extent; however, the phenomenon of Chinese traditional culture aphasia appears at the same time, which reveals English majors' deficiency in traditional cultural quality. This paper, based upon this problem, tries to put forward some methods to improve traditional cultural quality in English majors.
\end{abstract}

Keywords: English major, traditional cultural quality, cultivation

\section{Introduction}

In recent years, China's economic power and comprehensive national capacity have all been strengthened considerably, which gives China greater discourse right and makes Chinese culture more acceptable. Nowadays, Chinese traditional culture is favored by more foreigners and Chinese craze has appeared. Nevertheless, Chinese college students, especially English majors have weakened their traditional cultural quality, reflecting the disadvantages of college entrance examination and talent-training plan for college English majors. Therefore, attention should be paid to the cultivation of traditional cultural quality in the process of nurturing college English majors.

\section{Importance of Improving Traditional Cultural Quality in English Majors}

Language is an explicit feature of a country's nationality and cultural characteristics. At present, China has established a closer relationship with other countries with the globalization of economy, and at the same time, cross-language communication and intercultural communication have become an essential part in global interaction and communication (LI, 2016). China now has enhanced comprehensive strength and deepened the reform and opening up, demanding college English majors to apply their knowledge in international economic exchanges and cultural communications. Under this circumstance, Chinese college English majors have shouldered heavy responsibilities to disseminate outstanding traditional Chinese culture and accept achievements

YANG Yi, lecturer, M.A., School of Foreign Language, Leshan Normal University, Leshan, Sichuan, China. WANG Bing, lecturer, M.A., School of Foreign Language, Leshan Normal University, Leshan, Sichuan, China. Yang Yuan, professor, M.A., School of Foreign Language, Leshan Normal University, Leshan, Sichuan, China. 
from foreign civilizations. In addition, English majors are required to develop their foreign language proficiency and learn foreign cultures, and more importantly, to learn and understand traditional Chinese culture so as to spread profound Chinese culture. Only with professional language skills can the English majors put theory into practice and bring their specialties into full play. Good cultural quality is a bridge and the foundation in global communication, showing the mental outlook of China on the occasion of cultural and social transformation. It is meaningful for English majors to improve cultural quality and to learn traditional Chinese culture, which will deepen China's cultural exchanges with all other countries as well as strengthen China's capacity for international communications.

\section{Reasons for the Deficiency in Traditional Chinese Culture in College English Instruction}

Language is the carrier and an element of culture. In the process of English teaching, it cannot be ignored to guide students through learning traditional Chinese culture and improve traditional cultural quality. However, college English teaching about traditional Chinese culture is actually not satisfactory and needs to be improved.

\section{The Ignorance of Guiding Role of English Teaching Syllabus}

In the year of 2009, the English Teaching Syllabus for English Majors was issued by the Ministry of Education, which gives detailed description about the cultivation objectives. The syllabus requires colleges and universities to nurture versatile talents, which refers to the students who have a wide range of cultural knowledge including both British and American culture as well as traditional Chinese culture. However, traditional Chinese culture is overlooked while British and American culture is emphasized in college English instruction. As a result, Western festivals like Valentine's Day and Christmas are known to many English majors but not Spring Festival or Double-Seventh Day (Chinese Saint Valentine's Day), let alone the Chinese classical literary works and classics of pre-Qin (before $221 \mathrm{BC}$ ) Chinese thinkers. This kind of phenomenon fully displays that English majors are lacking in the traditional Chinese culture. It is worthy of our attention. After all, as a Chinese, Chinese traditional culture should come first compared with the Western cultures. Only when English majors have mastered the essence of Chinese traditional culture can they have a better and more meaningful communication with foreigners who want to learn about China and Chinese traditional culture. Therefore, the English Teaching Syllabus for English Majors should be given due attention.

\section{Improper Curricular Design and Lack of Traditional Chinese Culture Courses}

According to the survey, over 90 percent of colleges and universities have not arranged relevant courses about Chinese culture and only less than 10 percent colleges have arranged. But even so, most are elective courses. Many students choose them just for credit and both the teacher and students pay little attention to those courses. The reasons are as follows: On the one hand, teachers prepare for lessons carelessly and regard it as a teaching task, and on the other hand, students pay no attention to it and are unwilling to learn the course. Moreover, the teaching methods for those traditional Chinese courses still need to be polished and improved. Some teachers in the classroom have no idea of how to teach such courses about Chinese culture for the lack of interrelated teaching plan and teaching experience. Some teachers may just follow the textbook and explain the syntactic structure of the sentences or the new vocabularies in the passages, which bores the students a lot and does not capture the key points of teaching those courses about Chinese culture. Some other teachers may have 
applied improper teaching methods that students cannot understand the connotative meaning of Chinese culture or deep the understanding of the information involved (ZHOU \& LI, 2015).

\section{Inappropriate Textbook Design and Compilations}

Textbook designs and compilations are off-center. Although the teaching materials have changed many times and the old-fashioned part has been updated, the introduction to traditional Chinese culture is barely included. For the sake of Chinese English majors, the compilation committee of teaching materials has given deep and comprehensive descriptions about British and American culture in most textbooks, which provides good opportunities for English majors to learn and to understand foreign culture. However, it is undesirable to focus only on the foreign culture but neglect the important and wonderful traditional Chinese culture. It is putting the cart before the horse. Chinese English majors cannot forget who they are and what cultural background they live in. Beyond that, some textbooks about traditional Chinese culture are poorly arranged. The English expressions of traditional Chinese culture are not the technical ones, keeping English majors from developing their professional skills. Overall considerations have not been given to the contexts of the textbooks, which only describes one aspect of traditional Chinese culture. Furthermore, books about introducing traditional Chinese culture in English is scarce in the market, of which a large number of them cannot be used as textbooks. Without those guiding textbooks, Chinese English majors are in trouble learning new knowledge and understanding traditional Chinese culture.

\section{Methods of Improving Traditional Cultural Quality in College English Majors}

\section{Make Full Use of the Instruction in Classroom to Improve Cultural Quality in English Majors}

Classroom instruction is an essential element of English teaching and it is also an important way to improve the cultural quality in English majors (MAO, 2016). At present, many teachers have already realized the phenomenon of traditional Chinese cultural quality deficiency in English majors and already tried to change the current situation. Students are required to learn English expressions for Chinese culture after class and then to do related presentations. Besides, multimedia devices should be used to help English majors understand traditional Chinese culture. Students can choose to play a drama, play a short sketch, declaim a Chinese poem both in Chinese and English, and deliver a short speech about Chinese culture. With the application of classroom instruction, English majors will make good use of class time and leisure time to learn knowledge of traditional Chinese culture. Meanwhile, teaching Chinese culture is beneficial to correcting errors timely made by students as well as helps students to make up for each other's deficiencies and to share knowledge. English majors also can get perceptual knowledge via videos and audio files used in the class about traditional Chinese culture.

\section{Take Full Advantage of the Platforms like MOOC and Flipped Classroom to Cultivate Traditional Cultural Quality in English Majors}

MOOC and Flipped Classroom have become a universal phenomenon. Diversified teaching approaches like MOOC, Flipped Classroom, and Micro-lecture can be applied to improve traditional cultural quality in English majors. Besides, teachers should choose the way students prefer like online videos and recommend students to learn some online courses about Chinese culture. Moreover, many online Chinese culture courses are aimed at overseas students and some expressions in the courses are helpful to English majors. Making full use of those 
online courses and guiding students to learn Chinese culture is the goal of English teaching. If it goes on, interest will be aroused among students and students' scope of knowledge will be broadened. Students' sentiment will be shaped at the same time. Flipped Classroom is a brand new method of teaching, which allows students to learn the knowledge before the class and teachers to further explain the difficult knowledge that students still feel puzzled in class. Teachers can provide some videos or relevant materials about traditional Chinese culture before class begins and assign some homework after class while using the class time to help students collect and organize the materials as well as to nurture the critical thinking ability and traditional cultural quality. What the Chinese English majors should do is to collect related things about Chinese culture and then discuss them in class in English (LIU, 2016).

\section{To Improve Traditional Cultural Quality in English Majors in Daily Practice}

Practice is the best teacher. On-the-spot investigation and learning is the best way for English majors to fully understand the traditional Chinese culture. English teachers should fully utilize the local historical and cultural resources, supplying chances for students to do field-based learning at museums and scenic spots. Besides, museums now are equipped with advanced facilities and adopt bilingual interpretations, helping students to understand traditional culture and learn English expressions. English majors can also make a journey to visit Chinese scenic spots and historic sites in leisure time, so as to learn the anecdotes and history behind. Moreover, being a volunteer in Chinese scenic spots and historic sites is meaningful for English majors: On the one hand, students can introduce traditional Chinese culture to foreign visitors, and on the other hand, communication skills and comprehension capacity will be strengthened and traditional cultural quality will be improved.

\section{Conclusion}

Although the current situation of Chinese English majors' traditional cultural quality is disappointing to some degree because of a variety of some existing facts that need to be considered and changed, such as the improper curricular design and the lack of traditional Chinese culture courses, inappropriate textbook design and compilations, etc. we can still come up with some effective ways to improve the traditional cultural quality in college English majors, for example, we can take full advantage of the teaching time in the classroom and the teaching platforms after class, such as MOOC, to provide students with more opportunities to have a closer contact with Chinese traditional culture. Furthermore, to visit the places of interest in person is also a good way for English majors. They can experience the culture by seeing the English introductions to the temples, the ancient buildings, etc. I believe Chinese English majors' traditional cultural quality can and will be improved through the applications of such ways mentioned above.

\section{References}

LI, F. (2016). How to improve the cultural quality of English majors. Literature Education, 3, 82.

LIU, S. Y. (2016). Methods of improving the ability of expressing Chinese culture for English majors. Modern Communication, 24, 184-185.

MAO, J. S. (2016). On improving traditional Chinese cultural quality in English major. Journal of Liaoning Medical University (Social Science Edition), 3, 139-141.

ZHOU, P., \& LI, Y. (2015). On improving cultural quality in English major under multicultural sight. Journal of Heilongiiang College of Education, 1, 23-24. 